\title{
Copy number variation of lipocalin family genes for male-specific proteins in tilapia and its association with gender
}

\author{
A Shirak ${ }^{1}$, M Golik ${ }^{1}$, B-Y Lee ${ }^{2}$, AE Howe ${ }^{2}$, TD Kocher ${ }^{2}$, G Hulata ${ }^{1}$, M Ron $^{1}$ and E Seroussi ${ }^{1}$ \\ ${ }^{1}$ Institute of Animal Science, Agricultural Research Organization, Volcani Center, Beit Dagan, Israel and ${ }^{2}$ Department of Biology, \\ University of Maryland, College Park, MD, USA
}

\begin{abstract}
Lipocalins are involved in the binding of small molecules like sex steroids. We show here that the previously reported tilapia male-specific protein (MSP) is a lipocalin encoded by a variety of paralogous and homologous genes in different tilapia species. Exon-intron boundaries of $M S P$ genes were typical of the six-exon genomic structure of lipocalins, and the transcripts were capable of encoding 200 amino-acid polypeptides that consisted of a putative signal peptide and a lipocalin domain. Cysteine residues are conserved in positions analogous to those forming the three disulfide bonds characteristic of the ligand pocket. The calculated molecular mass of the secreted MSP $(20.4 \mathrm{kDa})$ was less than half of that observed, suggesting that it is highly glycosylated like its homologue tributyltin-binding protein. Analysis of sequence variations revealed three types of paralogs MSPA, MSPB and $M S P C$. Expression of both MSPA and MSPB was detected in
\end{abstract}

testis. In haploid Oreochromis niloticus embryos, each of these types consisted of two closely related paralogs, and asymmetry between MSP copy numbers on the maternal (six copies) and the paternal (three copies) chromosomes was observed. Using this polymorphism we mapped MSPA and $M S P C$ to linkage group 12 of an $\mathrm{F}_{2}$ mapping family derived from a cross between $O$. niloticus and Oreochromis aureus. Females with high MSP copy number were more frequent by more than twofold than males. Gender-MSPC combinations showed significant deviation from expected Mendelian segregation $(P=0.009)$ suggesting elimination of males with MSPC copies. We discuss different hypotheses to explain this elimination, including possibility for allelic conflict resulted by the hybridization.

Heredity (2008) 101, 405-415; doi:10.1038/hdy.2008.68; published online 23 July 2008

Keywords: sex determination; CNV; QTL; cichlidae; cichlid family; orosomucoid

\section{Introduction}

Sex determination (SD) in fish is poorly characterized and might frequently undergo evolutionary changes bringing the sex-determining cascade under new master sex regulators (Volff et al., 2007). True tilapias (Tilapiini) are a group of approximately 50 species of perch-like fishes, taxonomically divided into three genera Oreochromis, Sarotherodon and Tilapia (Trewavas, 1983; Majumdar and McAndrew, 1986). Several studies have identified genetic markers linked to sex in tilapia. Genetic mapping of genes for SD in purebred tilapia species indicated that SD may be regarded as a quantitative trait (Lee et al., 2004) and several linkage groups (LGs) were implicated. Lee et al. (2003) identified an XY system on LG1 in a strain of Oreochromis niloticus, and Lee et al. (2004) identified two epistatically interacting quantitative trait loci (QTL) - one on LG1 and the other on LG3 (Lee et al., 2004). QTL for sex-specific mortality (SSM) were detected on LG2, 6 and 23 in an inbred line of O. aureus (Palti et al., 2002; Shirak et al., 2002). Two distinct QTL for SD were also reported on LG23 in an $F_{2}$ hybrid cross

Correspondence: Dr E Seroussi, Institute of Animal Science, Agricultural Research Organization, Volcani Center, POB6, Beit Dagan 50250, Israel. E-mail:seroussi@agri.huji.ac.il

Received 19 March 2008; revised 6 May 2008; accepted 20 June 2008; published online 23 July 2008 between Oreochromis aureus and Oreochromis mossambicus (Cnaani et al., 2003, 2004).

A genetic linkage map in tilapia, based on an $F_{2}$ mapping family derived from a cross between two tilapia species: O. aureus and O. niloticus was previously reported (Lee et al., 2005). Male to female ratio in this family was skewed around two to three. In this family a major QTL for sex was mapped to a wide region of more than $13 \mathrm{cM}$ on LG3 (Lee et al., 2005), which did not provide complete explanation for gender variance nor for the skewed sex ratio.

Distortions from 1:1 sex ratio are common in tilapia interspecific crosses (Avtalion and Hammerman, 1978). These distortions were explained by (1) increased sensitivity of hybrids to environmental influence, including thermosensitivity (Desprez et al., 2006); (2) SSM (Shirak et al., 2002); and (3) imbalance in polygenic sex determination (Lee et al., 2004).

Cytochrome P450 aromatase catalyzing conversion of androgens to estrogens probably plays a critical role for ovarian differentiation in tilapia (Baroiller and D'Cotta, 2001). Exogenous androgens, estrogens, antiestrogens and aromatase inhibitors trigger sex reversal in tilapias, suggesting that they are sensitive to the levels of sex steroids at a critical period of development, like other fish species. In this period, environmental factors like temperature, $\mathrm{pH}$, density and social interactions influence sex ratio (Baroiller and D'Cotta, 2001). 
Another agent having endocrine-disrupting effect in fish and other aquatic organisms is tributyltin (TBT). This trialkyl organotin compound can induce masculinization in genetically females of Japanese flounder (Paralichthys olivaceus; Shimasaki et al., 2003) and affect sexual behavior and reproduction in medaka (Oryzias latipes; Nakayama et al., 2004). TBT accumulates in the serum of Japanese flounder as a complex with TBT-binding protein (TBT-bp; Shimasaki et al., 2002). Mature TBT-bp is heavily glycosylated (Hano et al., 2007) with a molecular mass of approximately $46.5 \mathrm{kDa}$, and only 191 amino acids with a lipocalin-like sequence pattern.

A similar protein was detected in the serum of sexually active males in different tilapia species as a male-specific electrophoretic band corresponding to a $41 \mathrm{kDa}$ protein (Avtalion et al., 1975; Avtalion, 1982). In dominant Sarotherodon galilaeus males the level of this male-specific protein (MSP) could achieve concentration of $5.2 \mathrm{mg} \mathrm{ml}^{-1}$, which is more than $1 \%$ of total serum proteins (Kirsh, 1991) and about fourfold higher than the concentration in average sexually active males. The level of MSP reaches a maximum at spawning time when MSP is also detectable in females (Trombka and Avtalion, 1993).

Adopting a candidate gene approach, we have systematically mapped genes that are potentially involved in SD and/or SSM of tilapias (Shirak et al., 2006b). The resemblance of sequence motifs between TBT-bp and MSP prompted us to characterize the latter genes in tilapia and study their possible role in SD.

\section{Materials and methods}

\section{Mapping family}

A red O. niloticus male from the University of Stirling stock (McAndrew and Majumdar, 1983) was crossed with a normally colored O. aureus female from an Israeli Mehadrin strain (Lee et al., 2004). The $\mathrm{F}_{2}$ family consisted of 156 offspring (61 males, 91 females and 4 unsexed individuals) of which 90 individuals were used for genotyping to create the second generation map (Lee et al., 2005).

\section{Collection of samples from other tilapia species and DNA extraction}

Fin samples of 40 individuals from different tilapia species and strains (detailed in Table 1) were collected for DNA extraction and sequencing in order to determine and compare MSP copies. DNA was extracted from fin tissue by the salting out procedure (Ma et al., 1996).

\section{Production and analysis of haploid embryos}

UV-irradiated Tilapia zillii sperm was used for the induction of gynogenetic haploids in eggs of a single Ghana-BIU O. niloticus female carrying the three MSP types according to procedure previously described (Shirak and Avtalion, 2001). This was followed by lysis of embryonic tissue from the haploids and DNA extraction (Gates et al., 1999). Tracefiles and Genome Assembly Program 4 (GAP4) database including assembled and annotated sequences of type-specific PCR products obtained from the haploid embryos is downloadable at http://cowry.agri.huji.ac.il/MSP/. PCR amplification reactions $(10 \mu \mathrm{l})$ were performed using Super-Therm polymerase (0.5 U; JMR Holdings, St Louis, MO, USA) according to the instruction of the manufacturer in the following conditions: 33 cycles for $40 \mathrm{~s}$ at $92^{\circ} \mathrm{C}, 30 \mathrm{~s}$ at $61^{\circ} \mathrm{C}$ and $1 \mathrm{~min}$ at $72^{\circ} \mathrm{C}$. PCR products were separated and sequenced as described in the next section.

\section{Prediction of intron-exon borders, PCR primer design and sequence analysis}

Genomic and expressed sequence tag sequences related to MSP were detected using the Basic Local Alignment Search Tool programs on the National Center for Biotechnology Information/National Institutes of Health server (http://www.ncbi.nlm.nih.gov/BLAST). Primers were designed with Primer3 (http://www-genome.wi. mit.edu/cgi-bin/primer/primer3_www.cgi) and PCR

Table 1 MSP gene types in different tilapia species and strains

\begin{tabular}{|c|c|c|c|c|c|}
\hline Species & Strain $^{\mathrm{a}}$ & Sample size & Females & Males & MSP paralogs ${ }^{b}$ \\
\hline \multirow[t]{6}{*}{ O. niloticus } & Stirling Red & 3 & 1 & 2 & $M S P A, M S P B$ \\
\hline & Swansea & 2 & 1 & 1 & $M S P A, M S P B$ \\
\hline & Ghana-Dor & 6 & 3 & 3 & $M S P A, M S P B$ \\
\hline & & 2 & 2 & 0 & $M S P A, M S P B, M S P C$ \\
\hline & Ghana-BIU & 2 & 1 & 1 & $M S P A, M S P B$ \\
\hline & & 2 & 2 & 0 & $M S P A, M S P B, M S P C$ \\
\hline \multirow[t]{6}{*}{ O. aureus } & Mehadrin & 5 & 2 & 3 & $M S P A, M S P B$ \\
\hline & & 2 & 2 & 0 & $M S P A, M S P B, M S P C$ \\
\hline & Stirling & 2 & 1 & 1 & $M S P A, M S P B$ \\
\hline & Ein Feshka & 2 & 1 & 1 & $M S P A, M S P B$ \\
\hline & Lake of Galilee & 2 & 1 & 1 & $M S P A, M S P B$ \\
\hline & BIU-1 line & 2 & 1 & 1 & $M S P A, M S P B$ \\
\hline \multirow[t]{2}{*}{$\mathrm{F}_{1}$ hybrids } & Mapping family & 1 & 0 & 1 & $M S P A, M S P B$ \\
\hline & & 1 & 1 & 0 & $M S P A, M S P B, M S P C$ \\
\hline O. mossambicus & Natal-Volcani & 2 & 1 & 1 & $M S P A$ \\
\hline S. galilaeus & Volcani & 2 & 1 & 1 & $M S P A$ \\
\hline T. zillii & Yarkon River & 2 & 1 & 1 & $M S P A$ \\
\hline Total & & 40 & 22 & 18 & \\
\hline
\end{tabular}

Abbreviation: MSP, male-specific protien.

${ }^{a}$ Various experimental strains held at the ARO aquaculture research unit, or recently collected from various locations in Israel.

'The presence of the paralogs was determined by analyzing sequencing chromatograms (see below in the 'Results' section). 
Table 2 PCR primer pairs used for the characterization of MSP genes

\begin{tabular}{|c|c|c|c|c|c|}
\hline \multirow[t]{2}{*}{ No. } & \multirow[t]{2}{*}{ Forward } & \multirow[t]{2}{*}{ No. } & \multirow[t]{2}{*}{ Reverse } & \multicolumn{2}{|c|}{ Amplicon } \\
\hline & & & & Spans & Size $(b p)^{\mathrm{a}}$ \\
\hline 1 & TCTGGAGGATCGTAGCAAGG & 2 & TGGCAGTGACATTTCCATGA & Introns 1 and 2 & 831 \\
\hline 3 & GGAAATGTCACTGCCACCTTC & 4 & CCAAGATGCTCATGACTGGA & Intron 3 & 168 \\
\hline 5 & TGGAACATCAGACAGCGAAG & 2 & TGGCAGTGACATTTCCATGA & Intron 2 & 454 \\
\hline 6 & tet-AACTCCCTGAGGCCTGAATC & 7 & CСACATGCATAAACATGCTC & Microsatellite & 180 \\
\hline
\end{tabular}

${ }^{a}$ Average size; variants slightly differ in length according to their microsatellite content.

fragments were amplified using BIO-X-ACT Long DNA polymerase kit (Bioline Ltd, London, UK) according to the instructions of the manufacturer and the following conditions: 30 cycles for $30 \mathrm{~s}$ at $92^{\circ} \mathrm{C}, 40 \mathrm{~s}$ at $63^{\circ} \mathrm{C}$, and $1 \mathrm{~min} \mathrm{~kb}^{-1}$ at $68^{\circ} \mathrm{C}$. Primer pairs for the amplification of introns are described in Table 2. PCR products were separated on agarose gels, excised from the gel, purified with DNA Montage Gel Extraction Kit (Millipore, Bedford, MA, USA) and then sequenced using an ABI 3700 sequencer. Sequences were assembled and compared using the GAP4 program (Staden et al., 2000). Protein sequences were aligned with ClustalW (http://clustalw. genome.jp), using default settings and Gonnet weight matrix. The graphical image of the multiple alignment was made using BoxShade (http://www.ch.embnet.org/ software/BOX_form.html). Predicted molecular mass was calculated with PeptideMass (http://www.expasy. $\mathrm{ch} /$ tools/peptide-mass.html) using default values.

\section{Type-specific PCR amplification in $O$. niloticus and $O$. aureus}

To determine and compare sequences of the three MSP gene types we used one forward primer (no. 1; Table 2) designed at the end of exon 1 and three different reverse primers with the consensus sequence AAATATCGA CAATTACGCTaTGN when ' $\mathrm{N}$ ' represents $\mathrm{T}$, $\mathrm{C}$ or A nucleotides for $M S P A, M S P B$ or $M S P C$, respectively. ' $\mathrm{N}$ ' is positioned at the unique base at the end of the second exon that distinguishes between these genes. Henceforth, this base position, seven nucleotides before the exon end, will be denoted MSP reference base (MSPrb). A mismatch at the fourth position from the primers' ends, indicated by lower case letter in the consensus sequence, was introduced to increase the specificity of the PCR amplification. PCR amplification reactions and sequencing was performed as above described in the section of analysis of haploid embryos.

\section{Tissue collection for the expression examination}

Two males and four females of O. niloticus Ghana-Dor (weight 200-350 g) were separated to a 1001 aquarium. Two days later, when male and females demonstrated the prespawning behavior, they were dissected, and samples of liver, testis and pronephros were collected. Dorsal fin samples were collected and stored in 70\% ethanol, whereas internal organs were kept in RNAlater (Ambion, Austin, TX, USA). Type-specific PCR analysis of genomic DNA (see 'Results') indicated that females and males were carriers of three and two MSP paralogs, respectively.

RNA extraction and analysis for gene expressions study Tissue sections $(0.5 \mathrm{~g})$ of liver, testis and pronephros were stabilized in RNAlater (Qiagen $\mathrm{GmbH}$, Hilden, Germany).
RNA was extracted from samples $(50 \mathrm{mg})$ immediately following homogenization in TRIzol (Gibco-BRL, Gaithersburg, MD, USA), according to the instructions of the manufacturer. Concentrations of 3.5-6 $\mu \mathrm{g}$ RNA per $\mu \mathrm{l}$ in final volume of $400 \mu \mathrm{l}$ were obtained. MSP cDNA was reverse transcribed and PCR amplified using $10 \mathrm{pmol}$ of each primer (no. 1 and no. 2; Table 2). Reverse transcription was performed using $1 \mu \mathrm{g}$ RNA in a total volume of $20 \mu \mathrm{l}$ using $200 \mathrm{U}$ SuperScript (Invitrogen, Carlsbad, CA, USA) according to the instructions of the manufacturer. Intronless products were sequenced and analyzed.

\section{Genotyping of microsatellite marker}

Genotyping of microsatellite DNA marker in the first intron of MSP gene was performed as previously described (Palti et al., 2002) using dye-labeled primers (no. 6 and no. 7; Table 2). To better distinguish between the alleles that differ in one base, the procedure was modified to use high fidelity Accuzyme DNA polymerase (Bioline Ltd, London, UK). Genotyping was performed using as template the PCR product obtained from type-specific PCR amplification. Prior to use, this product $(1 \mu \mathrm{l})$ was treated by shrimp alkaline phosphatase (SAP $2 \mathrm{U}$; Promega, Madison, WI, USA) in $5 \mu \mathrm{l}$ reaction containing SAP buffer, for $1 \mathrm{~h}$ at $37^{\circ} \mathrm{C}$ following with heat inactivation at $65^{\circ} \mathrm{C}$ for $15 \mathrm{~min}$.

\section{Genotyping of MSPrb}

Analysis of variation in copy number of the MSP genes was performed using DNA MassArray technology (Jurinke et al., 2001). PCR primers were designed using Sequenom's assay design software. For the first PCR amplification ACGTTGGATGGCCTTGAAGGTAGTAC AAATC and ACGTTGGATGCCATACCTGACAGTGA AGAC primers were used. The extension primer CAAAT ATCGACAATTACGCTTTG, positioned downstream of MSPrb was used for the second PCR.

\section{Linkage mapping}

Genotype data for the MSP genes (MSPA1, MSPA2, $M S P C 1$ and MSPC2) was added to genotype data of the mapping family for 545 markers, and mapping was performed using JoinMap software (3.0) as previously described (Lee et al., 2005). We were not able to detect sequence variation between MSPB homologues and therefore this group of genes was not mapped.

\section{Statistical comparison of models for SD and SSM}

In order to evaluate and compare the effects of the MSPA-MSPC locus on SD and SSM, we built two statistical models. For this analysis, out of the 156 F2 individuals of the mapping family, we considered the 
Table 3 Expected distribution of MSP genotypes between females and males under the SD model

\begin{tabular}{lll}
\hline MSPA $_{214}-M S P C$ & Females & Males \\
\hline Present & $75-0.5 m+n$ & $0.5 m-n$ \\
Absent & $75-0.5 m$ & $0.5 m$ \\
\hline
\end{tabular}

150 sexed individuals that were nonsergeants for MSPA$M S P C$ genes. We hypothesized that prior effect of this locus the numbers of males $(m)$ and females $(150-m)$ should be equally distributed between the two classeswith or without the $M S P A_{214}-M S P C$ genotype. Under a SD model, the effect of the MSPA $A_{214}-M S P C$ genes may be increasing the number of females with $M S P A_{214}-M S P C$ by number $n$, resulting in $((75-0.5 m)+n)$ females with this genotypic combination, on account of the number of males with the same genotypic combination, which becomes $(0.5 m-n)$ (Table 3$)$.

Under a SSM model, MSPA-MSPC genes cause the elimination of $n$ males that carried the $M S P A_{214}-M S P C$ genotype. The expected segregations into the four classes, in a sample of 150 individuals, are calculated using the $(150 /(150-n)$ coefficient (Table 4$)$.

In both models, observed and expected segregations were used to solve the equations for minimal $\chi^{2}, n$ and $m$ values by Newton's method of optimization (Tseng, 1998).

\section{Results}

$M S P$ has a lipocalin signature motif typical of transporters of steroids

In a search for genes that may affect SD and sex reversal in tilapia, we encountered recent sequence information for male-specific protein (GenBank accession number, AAR19269) that was significantly similar (E-value of $2 \mathrm{e}-09$ ) to TBT-bps (30\% identity and $46 \%$ similarity to poTBT; $25 \%$ identity and $41 \%$ similarity to fhTBT; Figure 1). The alignment of the 200 predicted aminoacid residues of MSP with seven orthologous lipocalins (Figure 1) indicated that MSP had a similar domain structure including a signal peptide and a lipocalin domain with the three main structurally conserved regions (SCRs). The calculated molecular mass of MSP without the peptide leader (181 residues) was $20.4 \mathrm{kDa}$. Cysteine residues were present in the expected positions to form the three sulfide bonds of the lipocalin subfamily of retinol-binding protein-like proteins (Yamada et al., 2006). These cysteines were implicated in the folding of a ligand pocket that mediates steroid transport by lipocalins such as hsORM1, which significantly resembled MSP (17\% identity and 34\% similarity; Figure 1) and binds to progesterone (Albani, 2006).

\section{Exon-intron boundaries of the MSP gene are typical} to the lipocalin six-exon gene structure

In order to generate genetic markers that would allow studying possible association of MSP with gender in tilapia we searched this gene for polymorphisms using the genomic DNA of the grandparents and parents of the tilapia mapping family (Lee et al., 2005). We predicted the position of the intron-exon boundaries by aligning
Table 4 Expected distribution of MSP genotypes between females and males under the SSM model

\begin{tabular}{lcc}
\hline MSPA $_{214}-M S P C$ & Females & Males \\
\hline Present & $(75-0.5 m)(150 /(150-n))$ & $(0.5 m-n)(150 /(150-n))$ \\
Absent & $(75-0.5 m)(150 /(150-n))$ & $0.5 m(150 /(150-n))$ \\
\hline
\end{tabular}

Abbreviation: MSP, male-specific protien.

the partial MSP transcript (GenBank accession number, EF661585) with a transcript derived from Tetraodon nigroviridis (GenBank accession number, CR693561) capable of encoding a similar lipocalin (40\% identity and 65\% similarity; Figure 1) with six exons that have been previously determined (Ensemble gene, GSTENT00028694001). We amplified the first, second and third introns (331, 301 and $87 \mathrm{bp}$, respectively) using PCR primers designed in the flanking exons. All exonintron boundaries contained the canonical GT and AG intronic dinucleotides at the donor and acceptor splice sites, respectively (GenBank accession numbers, AM886141, AM886142 and AM886143). The position of these exonintron boundaries was in agreement with the six-exon structure typical of the lipocalin genes (Figure 1).

\section{Copy number variation and allele polymorphism of $M S P$ genes in the tilapia mapping family}

The sequence of PCR-amplified products spanning the second intron and parts of the adjacent exons displayed several ambiguous nucleotides in the matriarch (Mehadrin stock of O. aureus) and patriarch (Stirling Red $\mathrm{O}$. niloticus) of the mapping family (Figure 2a, lanes $\mathrm{Oa}$ and $\mathrm{On}$, respectively). At the end of exon 2 of the maternal sequence trace at the base denoted MSPrb, we observed an overlap of three nucleotides, that is A, G and $\mathrm{T}$ (Figure $2 \mathrm{~b}$ ), suggesting the presence of three MSP paralogs. Using type-specific PCR, which was based on MSPrb, we sequenced three distinct amplicons (GenBank accession numbers, AM886144, AM886145 and AM886146). The polymorphic nature of these sequences is exemplified in a stretch of 50 bases at the end of the second exon (Figure 2b) and in its corresponding translation (Figure 2c), where multiple nonconservative changes of amino acids were recorded. A model of inheritance with three types of paralogs explained all ambiguous nucleotides in the coding region. The existence of multiple variants within these types was evident from sequencing of the intronic regions, as was best exemplified by a region of the first intron that was rich in nucleotide repeats which we designated as MSP microsatellite. To better distinguish between these variants we used the products of the type-specific PCR amplification as a template for genotyping the microsatellite. This two-step procedure indicated that different combinations of length variants were associated with the MSPA (177, 178,179 and $214 \mathrm{bp}$ ), the MSPB (177 and $178 \mathrm{bp}$ ) and the MSPC (180 and $181 \mathrm{bp}$ ) types. ShiftDetector analysis (Seroussi et al., 2002) of the trace files obtained from sequencing of type-specific PCR products from individuals carrying different combinations of variants was in agreement with the observed length polymorphism. Arabic numerals were used to denote the closely related paralogs within the types according to the inheritance model suggested in discussion. 



Figure 1 Alignment of male-specific protein (MSP) with similar lipocalins. The ClustalW alignment of predicted amino-acid sequences of eight orthologous lipocalins from Homo sapiens (hsORM1, orosomucoid 1, CAA29229); Gallus gallus (ggOGHI, $\alpha_{1}$-acid ovoglycoprotein, ABU24464); Danio rario (dr, hypothetical protein XP_678073 isoform 1, TGIR Tentative Consensus



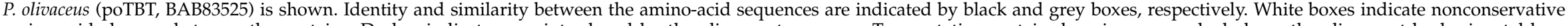

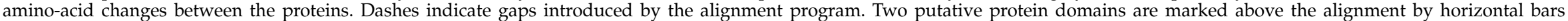





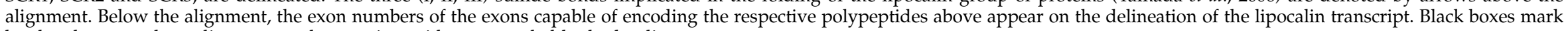
borders between the coding exons where amino acids are encoded by both adjacent exons. 
a

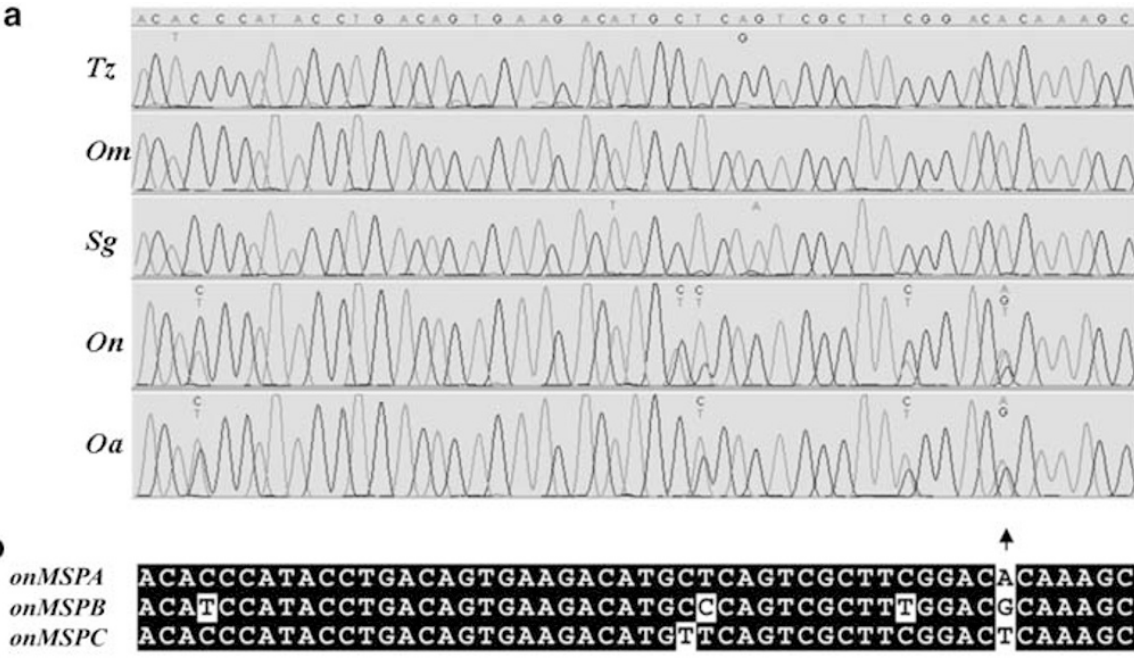

b onMSPC ACACCCATACCTGACAGTGAAGACATGTTCAGTCGCTTCGGACTCAAAGC
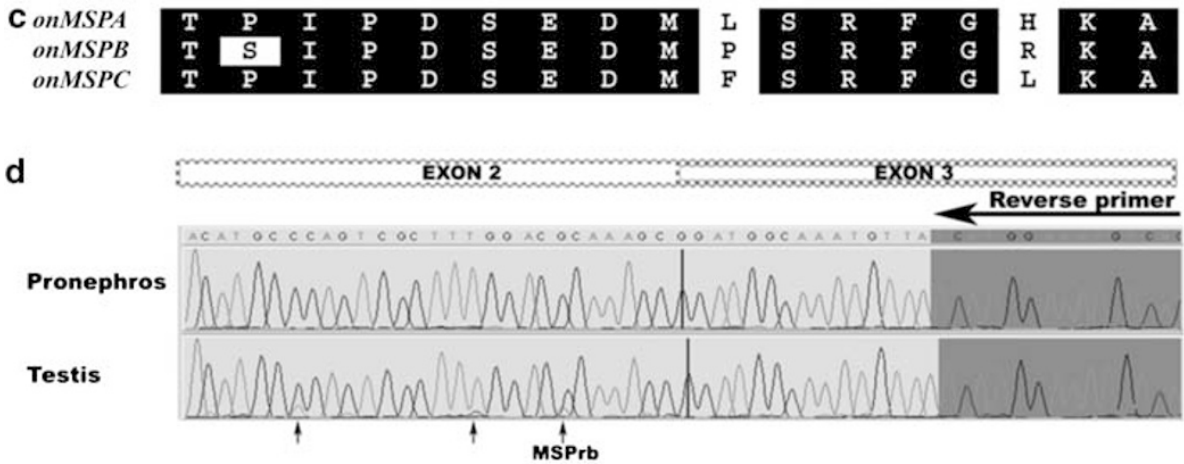

Figure 2 Sequencing of the second exon exemplifies the polymorphic nature of male-specific protein (MSP) genes. (a) PCR amplifications of $436 \mathrm{bp}$ products from the MSP loci were performed using oligonucleotide primers (no. 5 and no. 2; Table 2) designed according to the sequence of the second and third exons of S. galilaeus (GenBank accession number, AAR19269), respectively. The genomic DNAs of five tilapia species were used as template for this amplification: T. zillii (Tz); O. mossambicus $(\mathrm{Om})$; S. galilaeus $(\mathrm{Sg})$; O. niloticus $(\mathrm{On})$; O. aureus $(\mathrm{Oa})$. Above the lanes the sequence of the last $50 \mathrm{bp}$ of the second exon as recorded for $\mathrm{Om}$ is shown in one-letter color code (A, green; C, blue; $\mathrm{G}$, black; $\mathrm{T}$, red). Positions where the bases deviated from the $\mathrm{Om}$ sequence are indicated with the nucleotide code above the corresponding peaks. (b) Type-specific PCR was performed using DNA from the matriarch of the mapping family and the PCR products were sequenced. The sequence of the last $50 \mathrm{bp}$ of the second exon that corresponds to the chromatogram above is shown. Identity between the nucleotide sequences is indicated by black boxes. White boxes indicate nucleotide changes between variants. Arrow points to the polymorphism used to discriminate the three MSP paralogs (MSPrb). (c) Amino-acid translation of the sequences displayed in (b). Box shading follows the legend of Figure 1. (d) PCR amplifications of $142 \mathrm{bp}$ products from the MSP transcripts were performed using oligonucleotide primers (no. 1 and no. 2; Table 2). The presented chromatograms were obtained from the sequencing of reverse transcribed total RNA extracted from pronephros and testis of Ghana-Dor O. niloticus male. Above the lanes, similarly to what presented in (a), the sequence spanning the last $28 \mathrm{bp}$ of the second exon and $30 \mathrm{bp}$ of the third exon is shown in one-letter color code. Arrows below the chromatogram point to ambiguous bases including MSPrb where the simultaneous expression of MSPA and MSPB is detectable. Above the chromatogram boxes denote the exons and an arrow marks the sequence of the reverse primer (shaded).

\section{Copy number variation of $M S P$ genes among tilapia species}

MSPrb nucleotides of $\mathrm{A}, \mathrm{G}$ and $\mathrm{T}$, which are markers for $M S P A, M S P B$ and $M S P C$, respectively, were detected by sequencing in different tilapia species (Figure 2a; Table 1). In these samples we observed individuals with three MSPrb combinations: (1) singlet (A); (2) couplet (A and G) as in the grandfather and father of the mapping family, and (3) triplet (A, G and T) as in the grandmother and the mother of this family. Members of three different genera: O. mossambicus, S. galilaeus and T. zillii had only one copy of MSP (singlet, MSPA type). $O$. aureus and $O$. niloticus stocks and lines mostly had doublets except those that had triplets$O$. niloticus stocks that originated from Ghana (Dor and BIU; Table 1) and O. aureus from the Mehadrin stock. All seven individuals with triplets were females and none of the 18 males in the analyzed stocks had such a triplet (Table 1).

\section{Copy number variation of $M S P$ genes in Ghana O. niloticus}

By type-specific PCR, we showed the existence of the three types of MSP paralogs in haploid gynogenetic embryos derived from a female of Ghana O. niloticus, which had all three base variants for MSPrb, like the matriarch of the mapping family (Figure 3). Three of the embryos carried all three types of paralogs, whereas the other three carried only MSPA and MSPB. This is in concordance with the model suggesting that the diploid matriarch carries two sets of chromosomes, which differ in MSP copy number due to the presence or absence of MSPC type of genes. Sequencing of the PCR products of the first and second haploid embryos (Figure 3) revealed 


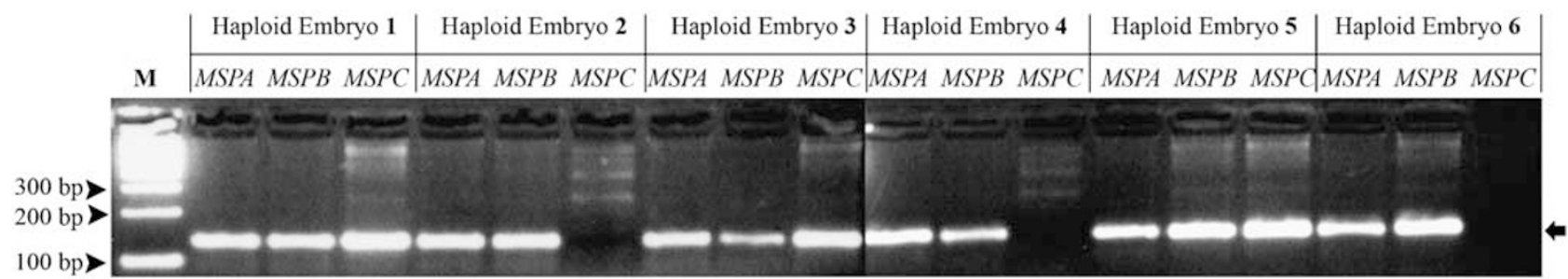

Figure 3 Type-specific PCR amplification of male-specific protein (MSP) genes from haploids. Ultraviolet (UV)-irradiated T. zillii sperm was used for the induction of gynogenetic haploids in eggs Ghana O. niloticus female carrier of the three MSP paralogs. Genomic DNA extracted from six embryos was used as a template for copy-specific amplification of $133 \mathrm{bp}$ PCR products using primers specific for MSPA, MSPB and $M S P C$, as indicated above the lanes. Arrows point to the molecular size standard (M), the PCR products.

Table 5 Detection of MSP paralogs in haploid embryos by sequencing and ShiftDetector analysis

\begin{tabular}{|c|c|c|c|c|}
\hline \multirow[t]{2}{*}{ Type-specific PCR } & \multicolumn{2}{|c|}{ Haploid embryo1 (MSPC carrier) } & \multicolumn{2}{|c|}{ Haploid embryo2 (MSPC noncarrier) } \\
\hline & No. of variants & Microsatellite sizes $(b p)$ & No. of variants & Microsatellite sizes ( $b p$ ) \\
\hline MSPA & 2 & $214,214^{\mathrm{a}}$ & 1 & 179 \\
\hline$M S P B$ & 2 & 177, 178 & 2 & 177, 178 \\
\hline MSPC & 2 & 180, 181 & & \\
\hline
\end{tabular}

Abbreviation: MSP, male-specific protien.

${ }^{\text {a }}$ The presence of a second variant was indicated by variation in sequence outside the microsatellite.

that these MSP types included at least six paralogs as indicated in Table 5. Existence of at least two paralogous variants was evident from ambiguous nucleotides along the sequence or from ambiguous traces following the indel site due to the difference in length of the MSP microsatellite. Asymmetry between the MSP copy number on the maternal chromosome represented by haploid embryo 1 and paternal chromosome (haploid embryo 2) was suggested (Table 5). Three extra copies on the maternal chromosome were evident, characterized by the presence of the MSPA $214 \mathrm{bp}$ variants $\left(M S P A_{214}\right)$ in combination with $M S P C$ variants.

\section{Expression of MSP paralogs}

To further assess if the MSP paralogs are functional genes, we examined the expression of MSP transcripts in three organs: liver, testis and pronephros using typespecific PCR in sexually active females and males (see details in 'Material and methods') with two and three MSP genomic copies, respectively. We sequenced the copy-specific PCR products and confirmed that they were derived from spliced transcripts corresponding to the expected exon structure (GenBank accession numbers, AM886144, AM886145, AM886146). MSPA was only detected in testis, whereas $M S P B$ was observed in testis and in pronephros of both the genders (Figure 2D). $M S P C$ was not detected in this experiment.

\section{Genetic mapping of MSPA and MSPC}

For linkage mapping of MSPA1 we used the microsatellite variations in the first intron of this gene. Mapping of MSPA2 gene was performed by defining the $214 \mathrm{bp}$ allele as absent or present. Similarly, MSPC was mapped by defining two genotypes ( $T$ absent or present) according to the status of MSPrb detected by mass spectrometry. This analysis detected simultaneously the three possible MSPrb variants. All genotypes were either couplet or triplets corresponding to the model of the patriarch and matriarch having MSPA and $M S P B$ or $M S P A, M S P B$ and $M S P C$, respectively. Genotypes were obtained for all 156 individuals of the $F_{2}$ mapping population. Among the 65 that inherited $M S P C, 63$ individuals also inherited $M S P A_{214}$, indicating tight linkage between these genes. The two groups of genes were mapped to two locations on LG12 with an interval of $2 \mathrm{cM}$ (Figure 4).

Association between gender and variability in MSP genes in the mapping family

Females with high MSP copy number were more frequent by more than twofold than males. The numbers for the four possible combinations of $M S P A_{214}-M S P C$ state with gender deviated significantly from the expected 1:1:1:1 Mendelian segregation $(P=0.009)$. The class of males with $M S P A_{214}-M S P C$ was clearly deficient compared to all other combinations (Table 6).

\section{Statistical comparison of models for SD and SSM}

The best solution of expected segregations under the SD model was obtained with values of 69 and 11 for $m$ and $n$, respectively, and yielded insignificant $\chi^{2}$ value $\left(\chi^{2}=3.844\right.$ and $\left.P=0.7207\right)$. On the other hand, the best solution of expected segregations under the SSM model was obtained with values of 71 and 18 for $m$ and $n$, respectively, was significantly more probable $\left(\chi^{2}=0.182\right.$ and $P=0.0192)$. Hence, we suggest that the $M S P A_{214^{-}}$ MSPC genotype induced SSM that resulted in eliminating 18 of the presumable $35.5(50.7 \%)$ males carrying this genotype.

\section{Discussion}

The alignment of the amino-acid sequence of MSP with orthologous proteins (Figure 1) indicated that it belongs to the lipocalin family of proteins. Among the 


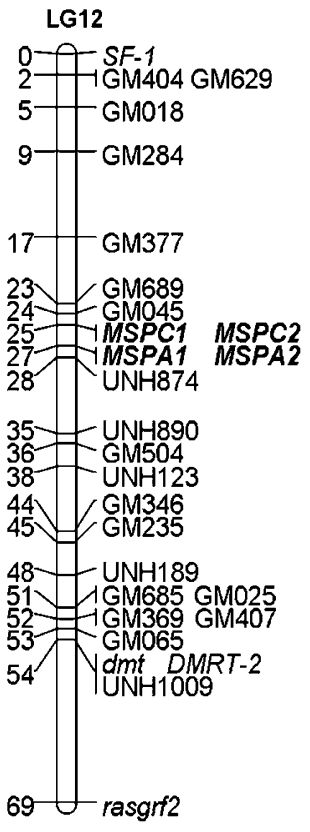

Figure 4 Genetic mapping of the male-specific protein A (MSPA) and the $M S P C$ groups of genes. Genotype data for the markers in the MSP genes (MSPA1, MSPA2, MSPC1 and MSPC2) and for the genetic markers of the mapping family were used as input for JoinMap software. The output for linkage group 12 (LG12) is presented in Centimorgans.

Table 6 Association between gender and high copy number of MSP genes in the mapping family

\begin{tabular}{lcc}
\hline MSPA $_{214}-M S P C$ & Females & Males \\
\hline Present & 43 & 20 \\
Absent & 47 & 40
\end{tabular}

Abbreviation: MSP, male-specific protien.

characterized lipocalin proteins of higher vertebrates it best resembled the highly glycosylated chicken ovoglycoprotein (ggOGCHI) and human orosomucoid 1 (ORM1). Indeed, high glycosylation level may explain the twofold incompatibility between calculated (20.4 kDa) and observed (41 kDa; Avtalion et al., 1975) molecular masses of MSP. Human ORM1 was also referred to as $\alpha_{1}$-acid glycoprotein that was implicated in mediating immune response by activated neutrophils (Theilgaard-Monch et al., 2005). The cluster of the three orosomucoid genes on mouse chromosome 4 is tightly linked to the cluster of another group of five lipocalins named major urinary proteins (Mups). ORM1 and Mup3 are also similar on the protein level (18\% identity and $39 \%$ similarity). The sex-dependent expression, association with sexual activity and extraordinary high level of MSP in tilapia serum (Avtalion et al., 1975, 1976) support the possibility that MSP is excreted in the urine or milt close to or during sexual intercourse. All the mentioned MSP properties highly resemble rat and mice Mups, whose expression is strongly stimulated up to 150-fold by androgens, principally by testosterone (Knopf et al., 1983). Mups play a role in pheromone binding and also are considered pheromones on their own (Flower, 1996).

Existence of genes orthologous to tilapia MSP genes in other species of fish is evident from similarity to poorly characterized genes in seabream $(\mathrm{lm})$, tetraodon $(\mathrm{tn})$ and zebrafish (dr) and to TBT-bps of flounder and killifish (Figure 1). Recent results in Japanese flounder showed that TBT-bp was also duplicated and that both paralogs were expressed in this species (Oba et al., 2007). Tandem triplication of the MSP-like genes is present in tetraodon (GenBank accessions, CR693561, CR702458 and CR719634). TBT induction of masculinization in genetic females of flounder (Shimasaki et al., 2003) further implies that the MSP genes, which encode TBT-bp-like proteins are associated with sexual functions and may influence SD.

Analysis of MSP sequence variation obtained by sequencing and genotyping of MSPrb and of the MSP microsatellite in the mapping family indicated that the four major types of gene combinations can be explained by a simple model of inheritance (Figure 5). Combining the genotyping data of MSPA microsatellite and copy status of MSPC with the available genotype data of our tilapia mapping family mapped $M S P A$ and $M S P C$ groups of genes to the same LG but $2 \mathrm{cM}$ apart. Furthermore, the high frequency of the nonconservative amino-acid exchange $(4 / 5=80 \%)$ relative to DNA sequence variations (Figure 2c) may indicate that they have diverted from their ancestral gene long enough to acquire different functions. This is also supported by the different patterns of MSP expression that were detected. Although MSPA was only detected in testis, MSPB was observed in the testis and in the pronephros of both genders and MSPC was undetectable.

MSP genes were mapped within a region of QTL for SSM that has not been previously described. Early studies relating SSM detected QTL on LG2, 6 and 23 in the different genetic background of an inbred line of O. aureus (Palti et al., 2002; Shirak et al., 2002). Previous study of the mapping family detected the observed effect; however, it was ignored as the study did not focus on the analysis of secondary QTL for SD (Lee et al., 2005). Analysis of association between the presence and absence of additional MSP copies and gender revealed that males with high copy number were twice as rare as expected. Comparison of observed segregations with those of statistical models supported this observation. Only the SSM model provides good explanation for the reduction in males with high MSP copy number, as a result of their specific mortality.

We propose two possible explanations for the association of male-specific mortality with the MSP copy number: (1) the additional MSP copies encode transporters for sex steroids which can directly connect SD and maturation with viability; and (2) male-specific mortality may be caused by another gene closely linked to the MSP genes on LG12.

The first hypothesis is in line with the observation that gene dosage in the evolution and function of vertebrate sex was associated with master-key genes for SD (Ferguson-Smith, 2007; Quinn et al., 2007; Volff et al., 2007). The domain structure of the MSP genes suggests that they are carriers of sex steroids and thus influence the most fundamental pathway of SD. Tilapia SD is highly sensitive to exogenous steroids. In tilapia hybrids, 



Figure 5 Inheritance of male-specific protein $(M S P)$ genes within the mapping family. A simplified model for inheritance of the observed $M S P$-variant combinations in a mapping family derived from a cross between O. niloticus and O. aureus was based on genotypes obtained by sequencing, genotyping of MSPrb and of MSP microsatellite. Excluding three recombinants, four major types of $F_{2}$ gene combinations (AC, $\mathrm{AB}, \mathrm{BC}, \mathrm{CC})$ were observed and denoted according to their origin: grand dam (GD, 29 individuals, AB), grand sire or sire (GS\&S, 46 individuals, BC), dam (D, 34 individuals, AC) and a new type (41 individuals, $C C)$. Each combination is described by delineation of the two homologous chromosomes on which the haplotypes consisting of MSPrb followed by the MSP microsatellite status are denoted. Shaded boxes present gene identities. Solid lines indicate mapped proximity and dashed ones suggest proximity yet to be detected. Bold solid lines show the gene flow between the generations.

it may have happened that driving MSP genes out of copy balance produced an effect of master-key regulator of SD for these genes. For example, at the second and third weeks after hatching in the hormone sensitive period for SD, transport of estrogens could have increased in individuals with high MSP copy number and thus skewing SD toward females. Appearance of new QTL for SD due to hybridization was predicted by an autosomal theory based on analysis of sex ratios in tilapia hybrids (Avtalion and Hammerman, 1978; Hammerman and Avtalion, 1979). In the present work we demonstrate the appearance of a new QTL for SSM due to hybridization, possibly due to MSP copy imbalance. Mortality resulting in reduced egg, embryo and larval survival also could have been brought about through TBT-bp, MSP homologue of medaka treated by TBT (Nirmala et al., 1999).

In support for the second hypothesis it should be noted that other strong candidate genes are located near the MSP locus, and that the six upper markers on LG12 (Figure 5) showed significant association with gender (data not shown). Most lipocalins are clustered on the same chromosome in several genomes, for example human chromosome 9 and mouse chromosome 2 (Chan et al., 1994; Suzuki et al., 2004). In humans this cluster consists of 16 characterized genes including ORM1 and ORM2 (9q32), odorant-binding proteins (9q34), progestagen-associated endometrial protein (9q34) and human prostaglandin D2 synthase (9q34.2-q34.4). The latter was proposed to be a key regulator of SD in mammals regulating the import and export of $S O X 9$ transcription factor from the nucleus, which are critical steps in the cascade of testis determination initiated by SRY (Malki et al., 2005). Another human gene NR5A1 (9q33) involved in the binding of steroid hormones, which is orthologous to the tilapia steroidogenic factor (SF1) implicated in primary SD (Shirak et al., 2006a, b), does not belong to the lipocalin family but was mapped close to this cluster both in human and tilapia.

One MSP copy of type MSPA was detected in species of three different genera-O. mossambicus, S. galilaeus and T. zillii, and two MSP copies were detected in most $O$. niloticus and $O$. aureus stocks from different origins. These results indicate that MSP duplication has probably occurred before the evolutionary divergence of these species. Three MSP copies were detected in females of O. aureus from Mehadrin stock and two stocks of $O$. niloticus both originated from Ghana. In a previous study we detected a high number $(36 \%)$ of $O$. niloticus alleles in the $O$. aureus Mehadrin stock, and suggested the possibility that this stock is not purebred (Shirak et al., 2006a). We hypothesize that MSP was primarily triplicated in the Ghana $O$. niloticus and later was introgressed into the $O$. aureus Mehadrin stock. Therefore, to identify the native role of all three MSP types of paralogs they should be studied in the Ghana O. niloticus strain. 


\section{Acknowledgements}

Genotyping of SNP was performed at the Genome Knowledge Center, the Weizmann Institute of Science, and the Crown Human Genome Center, Israel. We thank Tami Koch and Edna Ben-Asher from the Weizmann Institute of Science for operating the DNA MassArray technology. We acknowledge the help of Miri CohenZinder in performing the expression experiment. This research was supported by research grant nos. IS-3561-04 and IS-3995-07 from the United States-Israel Binational Agricultural Research and Development Fund. Sequence data from this article have been deposited with the EMBL/GenBank data libraries under accession numbers: AM886141; AM886142; AM886143; AM886144; AM886145; AM886146.

\section{References}

Albani JR (2006). Progesterone binding to the tryptophan residues of human alpha1-acid glycoprotein. Carbohydr Res 341: $2557-2564$.

Avtalion RR (1982). Genetic markers in Sarotherodon and their use for sex and species identification. In: Pullin RSV, McConnel RHL (eds). The Biology and Culture of Tilapias. ICLARM: Manila. pp 269-277.

Avtalion RR, Duczyminer M, Wojdani A, Pruginin Y (1976). Determination of allogeneic and xenogeneic markers in genus of tilapia-identification of $T$ aurea, $T$ vulcani and $T$ nilotica by electrophoretic analysis of their serum-proteins. Aquaculture 7: 255-265.

Avtalion RR, Hammerman IS (1978). Sex determination in Sarotherodon (tilapia).1. Introduction to a theory of autosomal influence. Bamidgeh 30: 110-115.

Avtalion RR, Pruginin Y, Rothbard S (1975). Determination of allogeneic and xenogeneic markers in the genus of Tilapia. I. Identification of sex and hybrids in Tilapia by electrophoretic analysis of serum proteins. Bamidgeh, Bull Fish Cult Israel 27: 8-13.

Baroiller JF, D'Cotta H (2001). Environment and sex determination in farmed fish. Comp Biochem Phys C 130: 399-409.

Chan P, Simonchazottes D, Mattei MG, Guenet JL, Salier JP (1994). Comparative mapping of lipocalin genes in human and mouse-the 4 Genes for complement C8-Gamma-chain, prostaglandin-D-synthase, oncogene-24P3, and progestagenassociated endometrial protein Map to HSA9 and MMU2. Genomics 23: 145-150.

Cnaani A, Hallerman EM, Ron M, Weller JI, Indelman M, Kashi Y et al. (2003). Detection of a chromosomal region with two quantitative trait loci, affecting cold tolerance and fish size, in an F-2 tilapia hybrid. Aquaculture 223: 117-128.

Cnaani A, Zilberman N, Tinman S, Hulata G, Ron M (2004). Genome-scan analysis for quantitative trait loci in an F-2 tilapia hybrid. Mol Genet Genomics 272: 162-172.

Desprez D, Briand C, Hoareau MC, Melard C, Bosc P, Baroiller JF (2006). Study of sex ratio in progeny of a complex Oreochromis hybrid, the Florida red tilapia. Aquaculture 251: 231-237.

Ferguson-Smith M (2007). The evolution of sex chromosomes and sex determination in vertebrates and the key role of DMRT1. Sex Dev 1: 2-11.

Flower DR (1996). The lipocalin protein family: Structure and function. Biochem J 318: 1-14.

Gates MA, Kim L, Egan ES, Cardozo T, Sirotkin HI, Dougan ST et al. (1999). A genetic linkage map for zebrafish: Comparative analysis and localization of genes and expressed sequences. Genome Res 9: 334-347.

Hammerman IS, Avtalion RR (1979). Sex determination in Sarotherodon (tilapia). 2. Sex-ratio as a tool for the determina- tion of genotype-model of autosomal and gonosomal Influence. Theor Appl Genet 55: 177-187.

Hano T, Oshima Y, Kim SG, Satone H, Oba Y, Kitano T et al. (2007). Tributyltin causes abnormal development in embryos of medaka, Oryzias latipes. Chemosphere 69: 927-933.

Jurinke C, van den Boom D, Cantor CR, Koster H (2001). Automated genotyping using the DNA MassArray technology. Methods Mol Biol 170: 103-116.

Kirsh N (1991). Quantitative study of the tilapia male-specific protein (MSP) in normal, sex inversed and gynogenetic tilapias. MSc thesis, Bar-Ilan University, Ramat-Gan, Israel.

Knopf JL, Gallagher JF, Held WA (1983). Differential, multihormonal regulation of the mouse major urinary protein gene family in the liver. Mol Cell Biol 3: 2232-2240.

Lee BY, Hulata G, Kocher TD (2004). Two unlinked loci controlling the sex of blue tilapia (Oreochromis aureus). Heredity 92: 543-549.

Lee BY, Lee WJ, Streelman JT, Carleton KL, Howe AE, Hulata G et al. (2005). A second-generation genetic linkage map of tilapia (Oreochromis spp.). Genetics 170: 237-244.

Lee BY, Penman DJ, Kocher TD (2003). Identification of a sexdetermining region in Nile tilapia (Oreochromis niloticus) using bulked segregant analysis. Anim Genet 34: 379-383.

Ma RZ, Beever JE, Da Y, Green CA, Russ I, Park C et al. (1996). A male linkage map of the cattle (Bos taurus) genome. J Hered 87: 261-271.

Majumdar KC, McAndrew BJ (1986). Relative DNA content of somatic nuclei and chromosomal studies in 3 genera, Tilapia, Sarotherodon, and Oreochromis of the tribe Tilapiini (Pisces, Cichlidae). Genetica 68: 175-188.

Malki S, Nef S, Notarnicola C, Thevenet L, Gasca P, Mejean C et al. (2005). Prostaglandin D2 induces nuclear import of the sex-determining factor SOX9 via its cAMP-PKA phosphorylation. EMBO J 24: 1798-1809.

McAndrew BJ, Majumdar KC (1983). Tilapia stock identification using electrophoretic markers. Aquaculture 30: 249-261.

Nakayama K, Oshima Y, Yamaguchi T, Tsuruda Y, Kang IJ, Kobayashi $\mathrm{M}$ et al. (2004). Fertilization success and sexual behavior in male medaka, Oryzias latipes, exposed to tributyltin. Chemosphere 55: 1331-1337.

Nirmala K, Oshima Y, Lee R, Imada N, Honjo T, Kobayashi K (1999). Transgenerational toxicity of tributyltin and its combined effects with polychlorinated biphenyls on reproductive processes in Japanese medaka (Oryzias latipes). Environ Toxicol Chem 18: 717-721.

Oba Y, Shimasaki Y, Oshima Y, Satone H, Kitano T, Nakao M et al. (2007). Purification and characterization of tributyltinbinding protein type 2 from plasma of Japanese flounder, Paralichthys olivaceus. J Biochem (Tokyo) 142: 229-238.

Palti Y, Shirak A, Cnaani A, Hulata G, Avtalion RR, Ron M (2002). Detection of genes with deleterious alleles in an inbred line of tilapia (Oreochromis aureus). Aquaculture 206: 151-164.

Quinn AE, Georges A, Sarre SD, Guarino F, Ezaz T, Graves JAM (2007). Temperature sex reversal implies sex gene dosage in a reptile. Science 316: 411.

Seroussi E, Ron M, Kedra D (2002). ShiftDetector: detection of shift mutations. Bioinformatics 18: 1137-1138.

Shimasaki Y, Kitano T, Oshima Y, Inoue S, Imada N, Honjo T (2003). Tributyltin causes masculinization in fish. Environ Toxicol Chem 22: 141-144.

Shimasaki Y, Oshima Y, Yokota Y, Kitano T, Nakao M, Kawabata $S$ et al. (2002). Purification and identification of a tributyltinbinding protein from serum of Japanese flounder, Paralichthys olivaceus. Environ Toxicol Chem 21: 1229-1235.

Shirak A, Avtalion RR (2001). Full-sib mating can reduce deleterious effects associated with residual sperm inheritance in gynogenotes. Isr J Aquacult Bamidgeh 53: 15-22.

Shirak A, Palti Y, Cnaani A, Korol A, Hulata G, Ron M et al. (2002). Association between loci with deleterious alleles and distorted sex ratios in an inbred line of tilapia (Oreochromis aureus). J Hered 93: 270-276. 
Shirak A, Seroussi E, Cnaani A, Howe AE, Domokhovsky R, Zilberman $\mathrm{N}$ et al. (2006a). Amh and Dmrta2 genes map to tilapia (Oreochromis spp.) linkage group 23 within quantitative trait locus regions for sex determination. Genetics 174: 1573-1581.

Shirak A, Seroussi E, Zilberman N, Hulata G, Ron M, Cnaani A et al. (2006b). Genetic basis of sex determination in fishes: Searching for master key regulator genes in the sex determination pathway of tilapias. Isr J Aquacult Bamidgeh 58: 350 .

Staden R, Beal KF, Bonfield JK (2000). The Staden package, 1998. Methods Mol Biol 132: 115-130.

Suzuki K, Lareyre JJ, Sanchez D, Gutierrez G, Araki Y, Matusik RJ et al. (2004). Molecular evolution of epididymal lipocalin genes localized on mouse chromosome 2. Gene 339: 49-59.

Theilgaard-Monch K, Jacobsen LC, Rasmussen T, Niemann CU, Udby L, Borup R et al. (2005). Highly glycosylated alpha 1-acid glycoprotein is synthesized in myelocytes, stored in secondary granules, and released by activated neutrophils. J Leukocyte Biol 78: 462-470.

Trewavas E (1983). Tilapiine Fishes of the Genera Sarotherodon, Oreochromis and Danakilia. British Mus. Nat. Hist.: London, UK, $583 \mathrm{p}$.

Trombka D, Avtalion R (1993). Sex determination in tilapia-a review. Isr J Aquacult Bamidgeh 45: 26-37.

Tseng CL (1998). A Newton-type univariate optimization algorithm for locating the nearest extremum. Eur J Oper Res 105: 236-246.

Volff JN, Nanda I, Schmid M, Schartl M (2007). Governing sex determination in fish:regulatory putsches and ephemeral dictators. Sex Dev 1: 85-99.

Yamada Y, Nakagawa K, Yajima T, Saito K, Tokushima A, Fujiwara K et al. (2006). Structural and thermodynamic consequences of removal of a conserved disulfide bond from equine beta-lactoglobulin. Proteins 63: 595-602. 